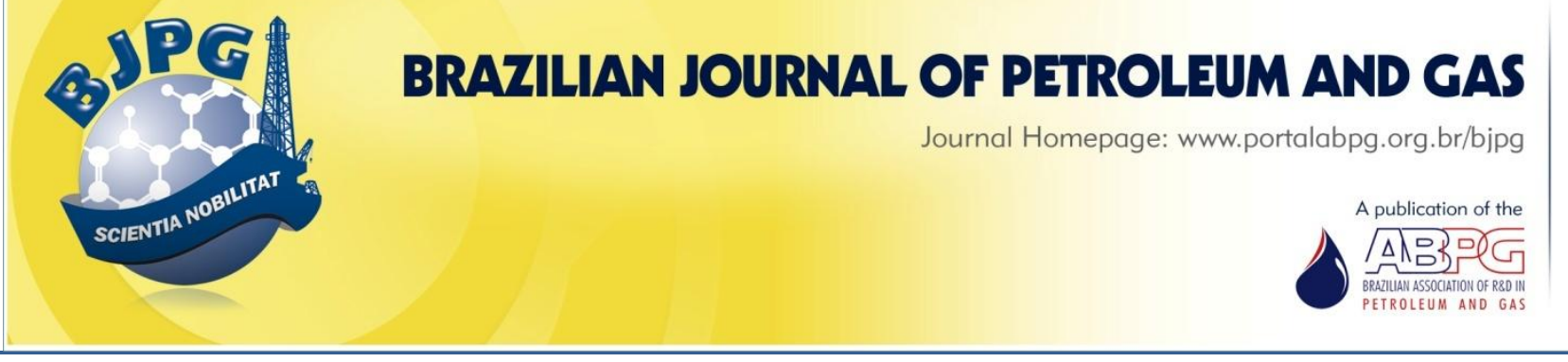

\title{
EFFECTS OF HIGH FLUID VISCOSITY ON PRESSURE LOSSES OF THE SINGLE-PHASE FLOW INSIDE AN ESP STAGE
}

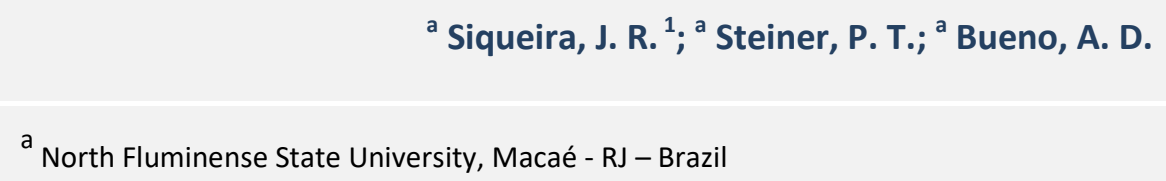

Received: 16.07.2019 / Revised: 28.08.2019 / Accepted: 01.09.2019 / Published on line: 08.10.2019

\begin{abstract}
The Electrical Submersible Pump (ESP) system is among the most widely used artificial lift methods in the world. This work studies the effects of high fluid viscosity on pressure losses of the flow in an ESP stage. A theoretical model was applied to four different flow cases. First, curves for head and pressure losses at the pump stage were generated and, based on literature formulations available in the model, as well as on adjusted empirical coefficients (for highly viscous fluids), implemented in the model. Subsequently, the heads were estimated and evaluated using experimental data and statistical analyses based on mean square error. The results showed that high fluid viscosity impacted considerably pressure losses and pump performance. In $50 \%$ of the cases studied, statistical analyses alone could estimate the head in the pump stage with good accuracy. However, in the remaining cases, it was also necessary to consider the physical behavior of the highly viscous fluids studied. The variability of the selected formulations from the literature (for pump head and pressure losses) with pump rotation, and especially with high fluid viscosity, was considerably larger than the ones found in previous studies for less viscous fluids.
\end{abstract}

\section{KEYWORDS}

electrical submersible pump (ESP); pressure losses; single-phase flow conditions; high fluid viscosity; head

\footnotetext{
${ }^{1}$ To whom all correspondence should be addressed.

Address: Laboratory of Meteorology, North Fluminense State University, Ave. Brennand, S/N, Parque Industrial Bellavista, Imboassica. Macae/RJ, Brazil.

ZIP Code: 27925-535 | Phone/Fax numbers: +55 22-27656535 / +55 22-27656531 | e-mail: siqueirajricardo@gmail.com doi:10.5419/bjpg2019-0018
} 


\section{INTRODUCTION}

The Electrical Submersible Pump (ESP) system is one of the most important artificial lift methods used in the oil industry (Thomas et al., 2001). The ESP system is described as follows. The energy is transmitted through an electric cable (generator) to an induction motor, where it is transformed into mechanical energy. The motor turns the shaft coupled to the multiple stages of the pump, which converts mechanical energy in hydraulic energy. The ESP system is formed by stages, where each stage consists of a moving part, called impeller, and a fixed (stationary) part called diffuser. The impeller provides velocity to the fluid due to the high rotation inside of its structure. Inside the diffuser, the flow is driven to the pump outlet (or to the next stage of the pump). To evaluate the performance of the ESP system, it is important to know the pressure losses inside the impeller and the diffuser at each pump stage. Pump performance curves are important because they describe pump power, head, and pressure losses. Thus, the knowledge of pressure losses is essential for estimating pump performance. In the petroleum industry, oils are characterized by very different viscosities, so oil viscosity impacts pressure losses inside an ESP stage and affects pump performance in different ways. This aspect was observed in several studies (Stepanoff, 1957; Estevam, 2002; Sun \& Prado, 2002; Amaral, 2007; Segala, 2010; Vieira et al., 2015).

Recent studies simulate the flow of highly viscous oils in different types of pumps (Paternost, 2013; Dunaiski, 2015; Zhu et al., 2016). According to Dunaiski (2015), an increase in fluid viscosity leads to an effect known as degradation. In this case, the viscous forces increase significantly and generate large energy dissipation, decreasing the pump head. This subject is also very important for the petroleum industry due to the fact that several oil basins are composed of high viscosity oils. These types of oils have become economically attractive due to recent discoveries of oil reservoirs in Canada, Venezuela, and Brazil, such as Campos Basin (Hein et al., 2017). Thus, it is essential to know how high fluid viscosities impact pressure losses of the flow in an ESP stage, as well as on ESP performance.

The objectives of this work are to estimate and analyze the different pressure flow losses in an ESP stage that are produced by high fluid viscosities, and evaluate high fluid viscosity effects on pressure losses and ESP performance. In this work, experimental head curves for an ESP stage are compared with head curves for an ESP stage simulated by a theoretical model. This theoretical model contains formulations for the following pressure losses in an ESP stage: impeller friction loss, impeller shock loss, impeller recirculation loss, diffuser friction loss, and disk friction loss. Four cases of ESP operations were studied (fluids with $720 \mathrm{cP}$ and $1020 \mathrm{cP}$, in rotations of $1800 \mathrm{rpm}$ and, especially, $3500 \mathrm{rpm}$ ). This work was carried out considering single-phase, Newtonian, incompressible, and isothermal flow.

\section{REVIEW OF CONCEPTS}

This section presents a description of flow in an ESP system and a literature review.

\subsection{Description of flow in an ESP system}

For a better understanding of the flow inside a centrifugal pump, it is necessary to represent the velocity vectors of the pump blades and the fluid passing through the pump impeller. Figure 1 shows the visualization of the radial impeller's geometry and the shape of a centrifugal pump channel crosssection. Within the impeller, several blades rotate around an axis at an angular velocity ? The peripheral (or circumferential) blade velocity is given by $\overrightarrow{\boldsymbol{U}}=\boldsymbol{\omega} \overrightarrow{\boldsymbol{r}}$, where $r$ is the radius. The absolute velocity (or fluid velocity, seen by a stationary observer outside the pump) is given by $V$. The relative velocity is given by $W=V-U$. The blade angle (or the relative angle $b$ ) is a geometric parameter of the pump that corresponds to the angle between the blade and the tangent line.

When the pump operates at the Best Efficiency Point (BEP), it is predicted that the angle $b$ between $W$ and $U$ is equal to the blade angle. In this condition, the flow is considered ideal because there are no disturbances, nor recirculation, or shocks inside the pump. As a result, there is a perfect guidance of the fluid inside the pump. In operating conditions outside the BEP, it was used a superscript " 1 " to identify these conditions. The not idealized angle $B$ (out of the BEP) is rewritten to $B_{1}^{\prime}$ at the impeller inlet and $B_{2}^{\prime}$ at the impeller outlet. 


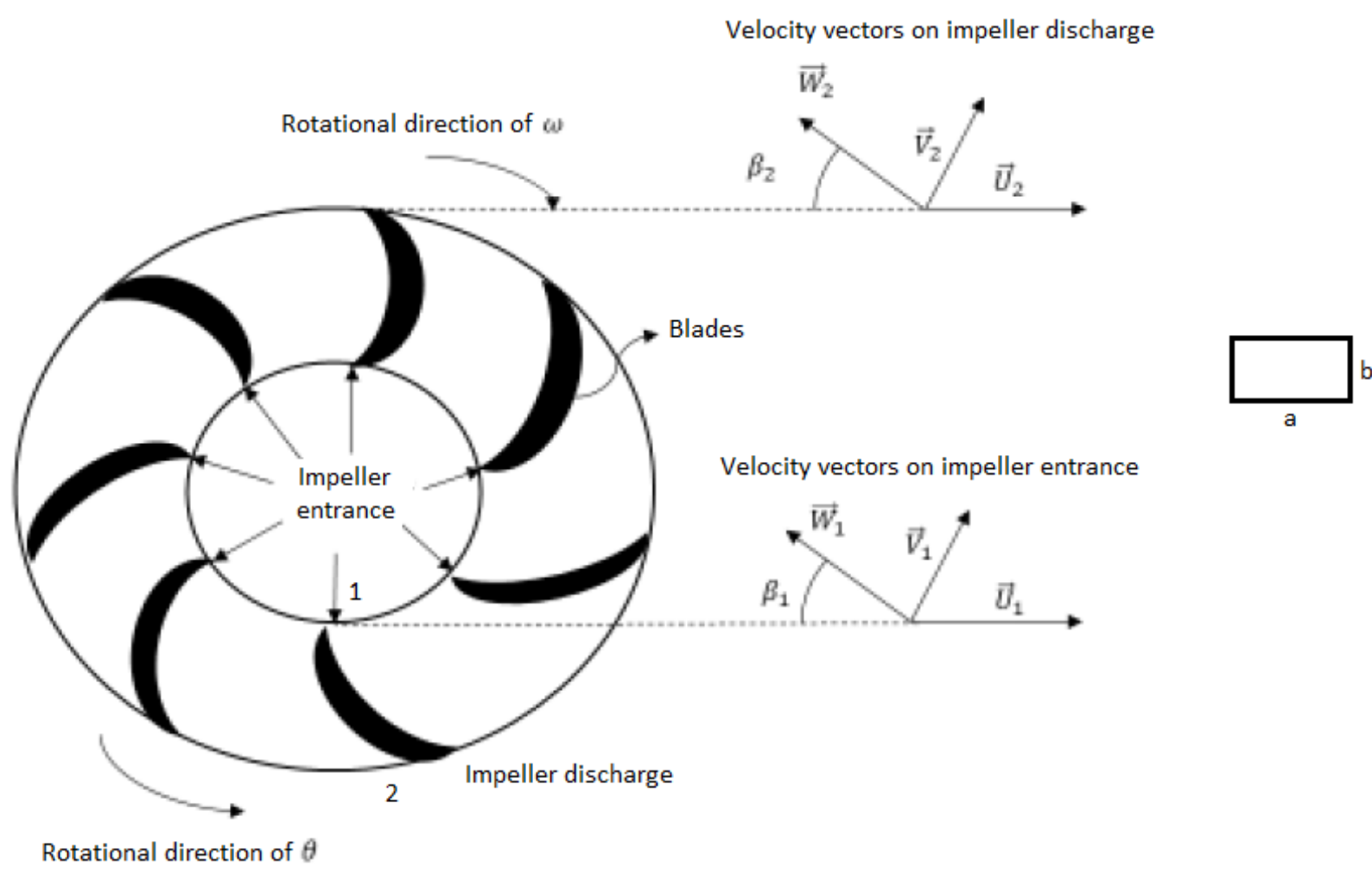

Figure 1. Visualization of the radial impeller's geometry and the shape of a centrifugal pump channel crosssection.

To represent a mixed flow pump used in the present work, it is essential to include a subtle change to the flow angle. In this type of pump, the radial flow is slightly upward. At mixed flow pumps, $\beta_{h}$ is the blade angle projection in the horizontal plane, and $\gamma$ is the angle between the blade and the horizontal plane when the rotor is analyzed longitudinally. For radial pumps, $\beta_{h}=\beta$, but for mixed ones, $\beta_{h}$ and $\beta$ are related by:

$$
\begin{aligned}
& \beta=\cos ^{-1}\left(\cos \beta_{h} \cos \gamma\right) \text { or } \\
& \beta_{h}=\arccos \left(\frac{\cos \beta}{\cos \gamma}\right)
\end{aligned}
$$

\section{LITERATURE REVIEW}

The theory of centrifugal pumps developed by Amaral (2007) was used in the present work to estimate the pump's head in an ESP stage. This theory is based on differential conservation equations of mass and momentum, and it considers a one-dimensional flow approximation. The head in a pump stage is given by:

$$
\begin{aligned}
& H=H_{\text {theoreticd }}-h_{\text {friction }}-h_{\text {shock }}- \\
& -h_{\text {recirculaton }}-h_{\text {diffuser }}-h_{\text {disk }}
\end{aligned}
$$

Based on Equation (2), the expressions of each term of the pump's head, as well as the different pressure losses present in a pump stage, are described below.

\subsection{Net theoretical head ( $\left.\boldsymbol{H}_{\text {theoretical }}\right)$}

The net theoretical head comes from the ideal centrifugal pump head (or Euler's head) modified by Amaral (2007) and other authors for non-ideal operating conditions of the pump. Table 1 shows the ten formulations for theoretical head existent in the theoretical model (see Equations 3 to 14). The correction factor in Equation 7 was used by Amaral (2007) to correct the angle and the velocities of the fluid at the impeller outlet. Other formulations consider the slip factor of the Wiesner's formula (Wiesner, 1967), as well as the Pfleiderer and Petermann's (1972) correction factors using the expression from Sun and Prado $(2002,2003)$. 
Table 1. Formulations and correction factors for the net theoretical head existent in the theoretical model.

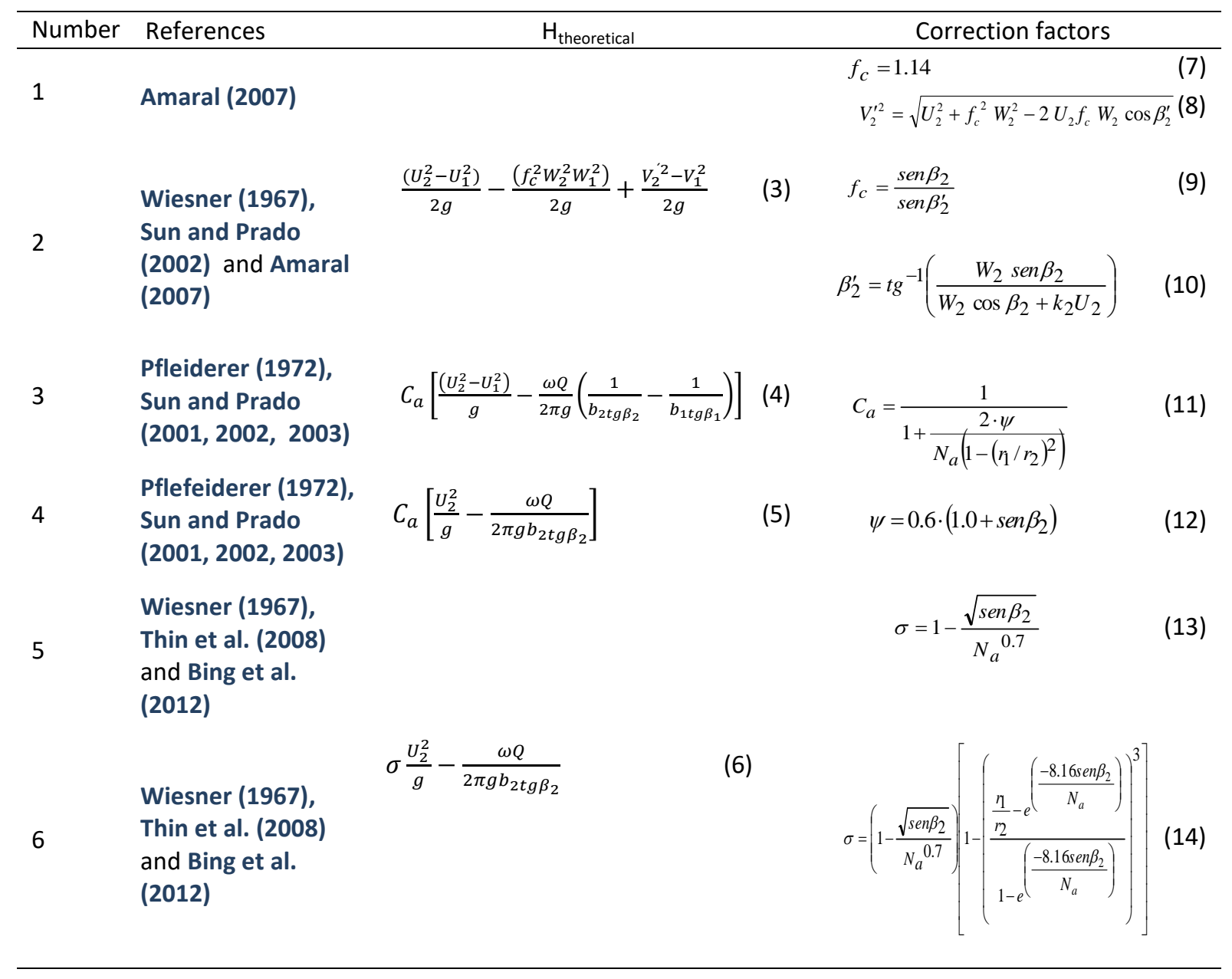

\subsection{Impeller friction losses $\left(\boldsymbol{h}_{\text {friction }}\right)$}

The impeller friction loss is caused by the viscous forces acting on the flow. Table 2 shows the six formulations and correction factors for the impeller friction loss existent in the theoretical model (see Equations 15 to 23). The formulations are based on Darcy's Law, so that some of them had to be adjusted in the present work (Bing et al., 2012; Thin et al., 2008). Some formulations use correction factors from Sun and Prado (2002, 2003).

\subsection{Impeller shock losses ( $\left.\boldsymbol{h}_{\text {shock }}\right)$}

The impeller shock loss is not caused by the physical impact of the fluid with the impeller blades, but by variations in flow direction, as described by Stepanoff (1957). Some authors describe this loss as a loss by incidence (Bing et al., 2012). Table 3 shows the formulations for impeller shocks loss and their corresponding correction factors existent in the theoretical model. The formulations of Stepanoff (1957) and Conrad et al. (1980) had to be adjusted in the present work by the correction factors of Thin et al. (2008) and Bing et al. (2012).

\subsection{Impeller recirculation losses ( $\left.\boldsymbol{h}_{\text {recirculation }}\right)$}

Table 4 shows the formulations for impeller recirculation loss and their corresponding correction factors existent in the theoretical model (see Equations 24 and 25). According to Thin et al. (2008), the impeller recirculation loss takes place via leakage of the fluid to other pump cavities. For these authors, losses by recirculation increase for smaller flow rates, where less energy is supplied to the flow. The shock losses coefficient had to be adjusted in the present work. 
Table 2. Formulations and correction factors for the impeller friction loss existent in the theoretical model.

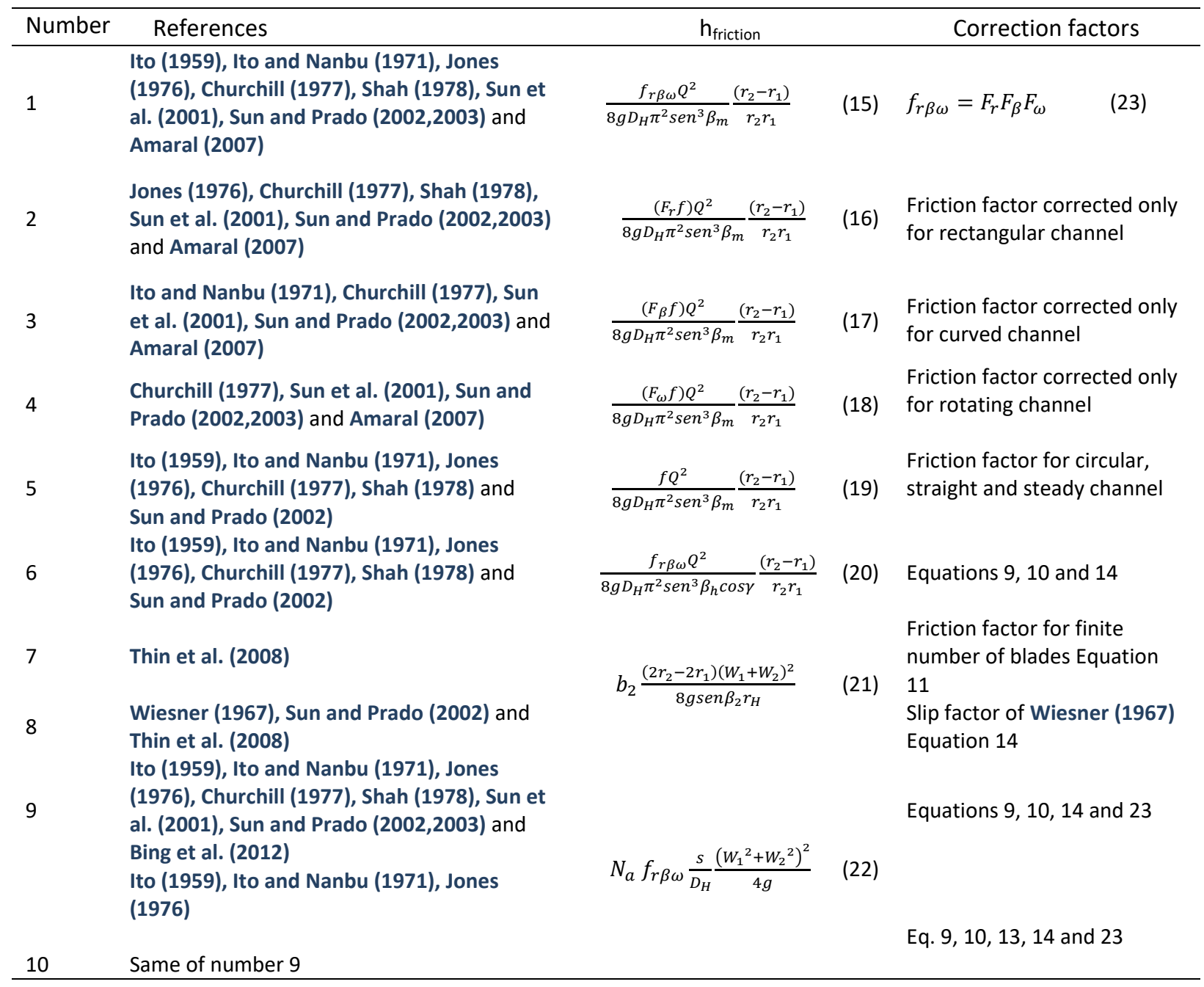

Table 3. Formulations and correction factors for the impeller shock loss existent in the theoretical model. The correction factors were adjusted in the present study for highly viscous fluids.

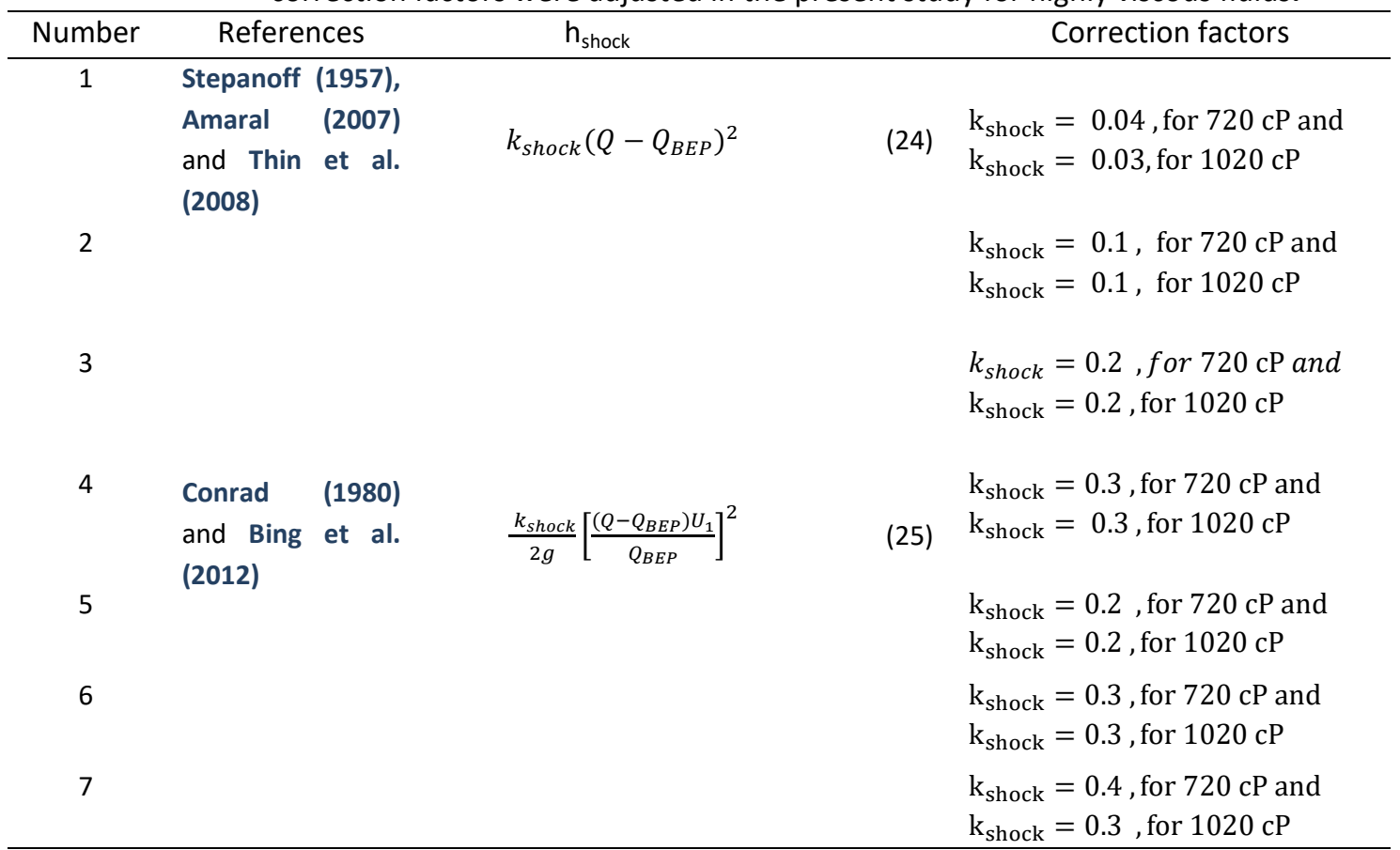


Table 4. Formulations and correction factors for the impeller recirculation loss existent in the theoretical model. The correction factors were adjusted in the present study for highly viscous fluids.

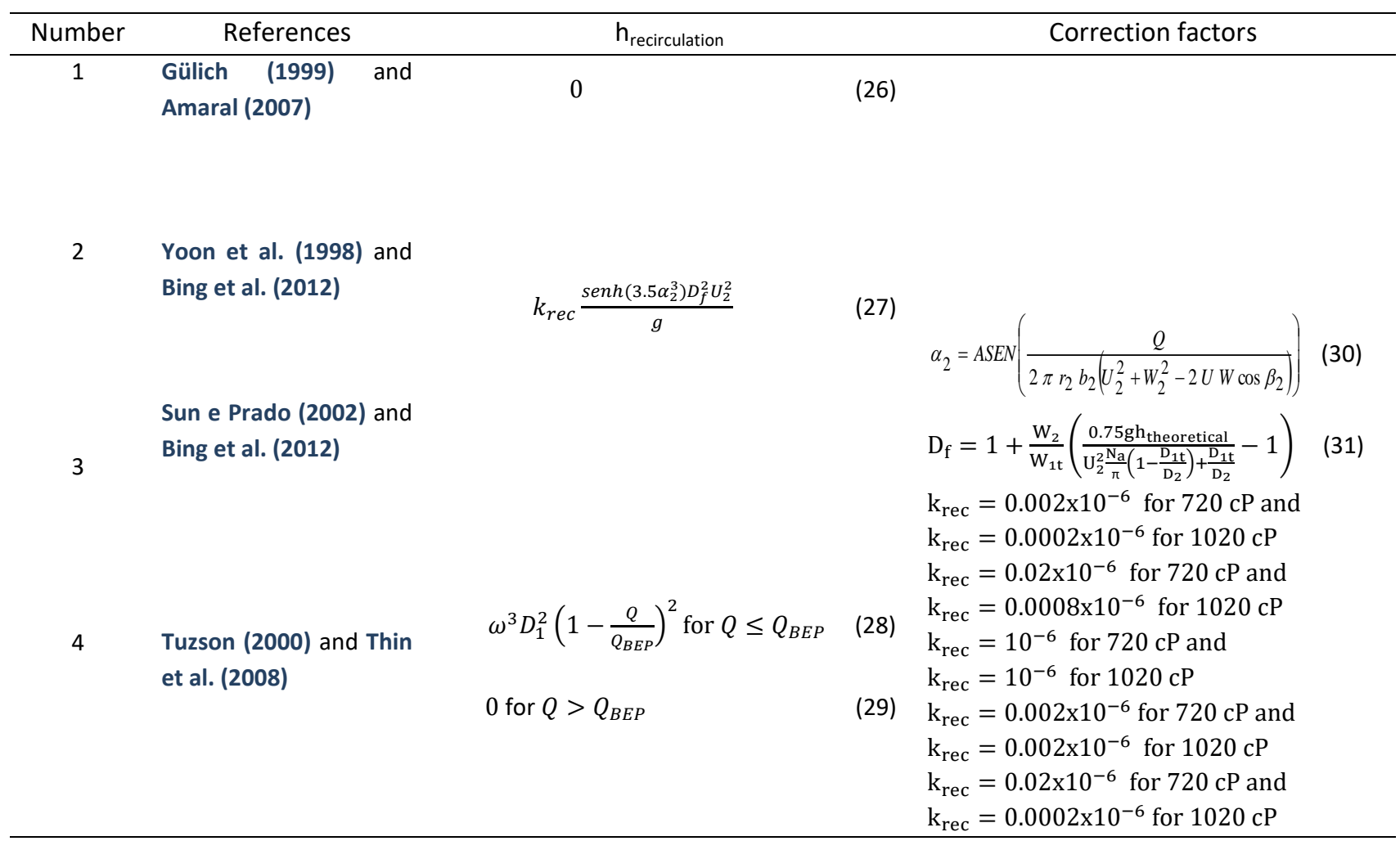

\subsection{Diffuser friction losses ( $\left.\boldsymbol{h}_{\text {diffuser }}\right)$}

Diffuser friction loss is relatively similar to impeller friction loss, except for this component of the pump is stationary (Sun \& Prado, 2002, 2003). Table 5 shows the formulations for diffuser friction loss and their corresponding correction factors existent in the theoretical model (see Equations 32 to 36). All the formulations are also based on Darcy's Law (Amaral, 2007; Sun \& Prado, 2002, 2003; Bing et al., 2012).

\subsection{Disk friction losses $\left(\boldsymbol{h}_{\text {disk }}\right)$}

As described by Stepanoff (1957), disk friction losses occur in the region between the impeller and the diffuser. Due to pump rotation, centrifugal forces act on the flow, making the fluid particles get out of the disk region. Other incoming particles in this region collide with those already present. Table 6 shows the formulations for disk friction loss and their corresponding correction factors existent in the theoretical model (see Equations 37 to 49). The coefficients of disk friction losses also had to be adjusted for some formulations in the present work.

\section{MATERIALS AND METHODS}

In the present work, the flow was modeled in a seven-bladed centrifugal pump, model GN7000, manufactured by Schlumberger-Reda with the purpose of estimating its actual head. This is a mixed flow pump type with flow rate, head, power, and efficiency at BEP equal to $1.175 \mathrm{~m}^{3} / \mathrm{d} ; 29 \mathrm{~m}$; $7.76 \mathrm{HP}$, and $66.55 \%$, respectively. The data used were obtained from the ESP experiment made by Amaral (2007), for four flow cases studied: $720 \mathrm{cP}$ and $3500 \mathrm{rpm}, 1020 \mathrm{cP}$ and $3500 \mathrm{rpm}, 720 \mathrm{cP}$ and $1800 \mathrm{rpm}$, and $1020 \mathrm{cP}$ and $1800 \mathrm{rpm}$. The main experimental data were: head on the pump stage $(H)$, flow rate $(Q)$, dynamic viscosity $(\mu)$, and pump rotation $(N)$. Some geometrical characteristics of the pump were also applied in this work.

This work used the theoretical (analyticalempirical) model in Fortran language, developed by Vieira et al. (2015), to estimate the head and the different pressure losses on the pump stage. The theoretical model computes the terms of the head equation for the pump stage (Equation 2) for all combinations of the main formulations from the literature (Tables 1 to 6 ). This model also validates 
BRAZILIAN JOURNAL OF PETROLEUM AND GAS | v. 13 n. 3 | p. 211-230 | 2019 | ISSN 1982-0593

Table 5. Formulations and correction factors for the diffuser friction loss existent in the theoretical model.

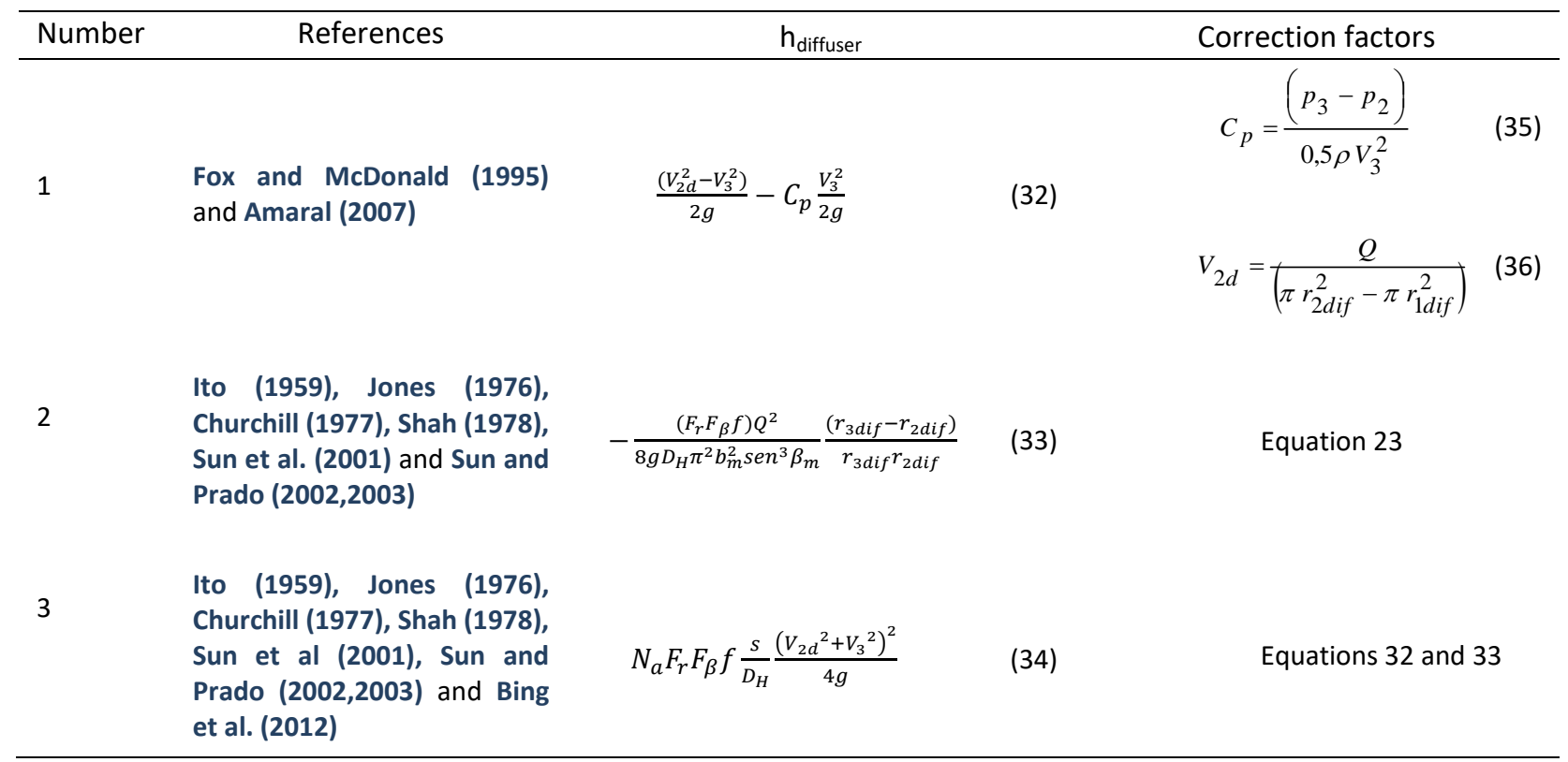

Table 6. Formulations and correction factors for disk friction loss existent in the theoretical model. The correction factors were adjusted in the present study for highly viscous fluids.

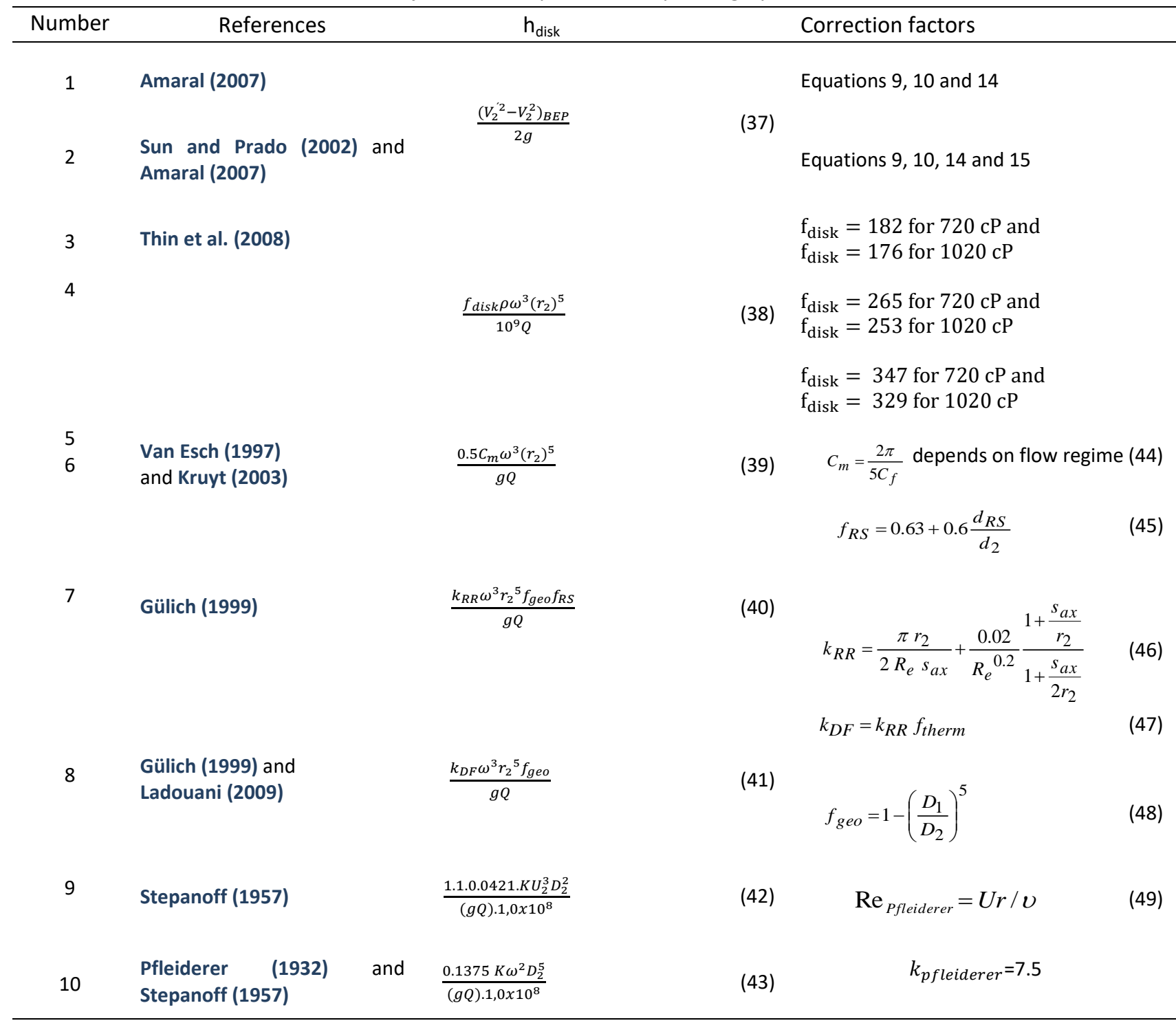


the formulations of pressure losses on the pump stage by comparing its estimated heads with the experimental head on the pump stage. The theoretical model also provides the results of root mean square error (RMSE) between each of the 100800 combinations of formulations (simulated heads) and the experimental head on a stage. The criterion used for selection of the best combination is based on the smaller RMSE between the head estimated by the theoretical model and the experimental head on pump stage. The RMSE corresponding to each head estimated by the theoretical model is given by:

$R M S E=\sqrt{\frac{1}{n} \sum_{i=1}^{n}\left(H_{i}-H_{E X P, i}\right)^{2}}$ in meters

where $n$ is the number of flow rate samples from the experiment of Amaral (2007), $H_{i}$ is the actual head on a pump stage estimated by the theoretical model for the $i$-th flow rate, and $H_{E X P, i}$ is the experimental head on a stage for the $i$-th flow rate. The model provides the most accurate theoretical formulations using a value for a user-selected RMSE value. Most details about the theoretical model can be found in Vieira et al. (2015).

It is important to point out that the empirical coefficients of some losses in the head equation on pump stage used by the theoretical model had to be adjusted for the high fluid viscosities studied in the present work. These adjusted empirical coefficients refer to the impeller shock loss, impeller recirculation loss, and disk friction loss (not shown).

\section{RESULTS E DISCUSSION}

This section is divided in net theoretical head and pressure losses in an ESP stage, analysis of pressure losses, and comparison with previous studies.

\subsection{Net theoretical head and pressure losses in an ESP stage}

Figures 2 and 3 show all the formulations for the net theoretical head of the pump and the various pressure losses that were calculated by the theoretical model. These formulations are presented only for the most important cases of flow studied: Case 1 (720 cP and $3500 \mathrm{rpm}$ ) and
Case 2 (1020 cP and $3500 \mathrm{rpm}$ ). Cases 1 and 2 refer to fluids containing high viscosity and very high viscosity, respectively, at higher flow rates. For the net theoretical head (Fig. 2a), the formulations that consider pre-rotation at the impeller entrance (first, second, and third in Table 1) provide curves of the net theoretical head increasing with flow rate. However, for the fourth, fifth, and sixth formulations in Table 1, which do not consider prerotation, one can observe a decrease of the net theoretical head with flow rate. Fourth, fifth, and sixth formulations are consistent with the pump theory that does not consider pre-rotation of the flow particles at impeller inlet (Sun \& Prado, 2002). No approach in the literature considers prerotation in the flow, such that a more detailed analysis of the first, second, and third formulations is not possible. The values for the net theoretical head obtained are slightly smaller than the ones estimated by previous studies for less viscous fluids (Amaral, 2007; Vieira et al., 2015). This shows that high fluid viscosity affects impeller performance, providing less energy to the flow in the pump stage.

By evaluating the impeller friction loss, it can be observed the same behavior concerning previous studies, but the values found in the present work are larger due to the presence of high fluid viscosities (Fig. 2b). First to sixth formulations in Table 2 resulted in smaller losses. These formulations presented relatively similar values, so that their corresponding types of correction factor appear to be less important in the estimation of their magnitudes. The remaining formulations in Table 2 showed a more rapid increase in the friction loss with flow rate. It is important to note that these formulations are based on Darcy's Law without a correction factor. Ninth and tenth formulations in Table 2 exhibited the highest friction loss values.

For the impeller shock loss, one can observe that the curves of all formulations had the same pattern (Fig. 2c), consistent with the one described by Bing et al. (2012). Shock losses decrease with flow rate at flow rates closer to the BEP one, and increase with flow rate at flow rates distant from the BEP one. This is because the flow angle at the impeller inlet is different from the blade angle in operational conditions distant from the BEP. The first to fourth formulations in Table 3 are based on the expression of Conrad et al. (1980). The 
(a)

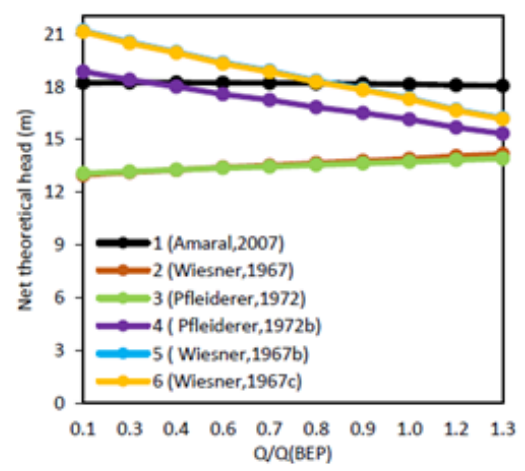

(c)

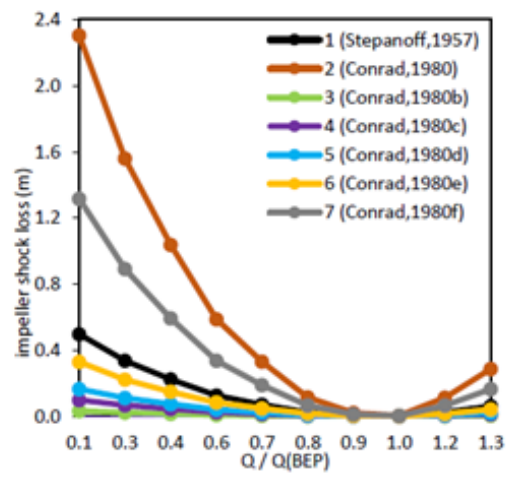

(e)

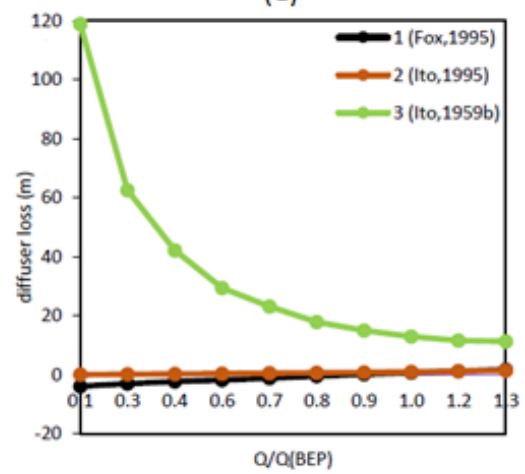

(b)

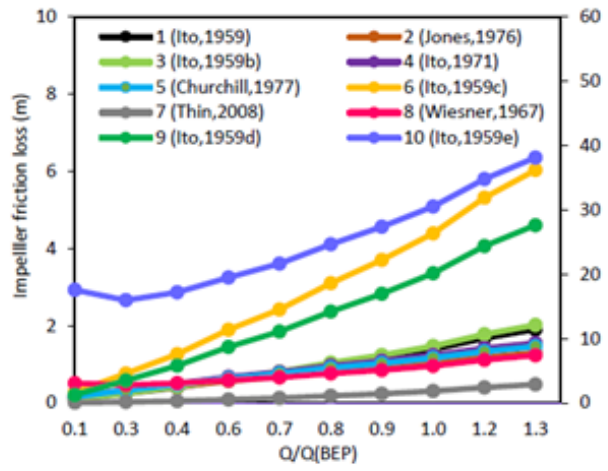

(d)

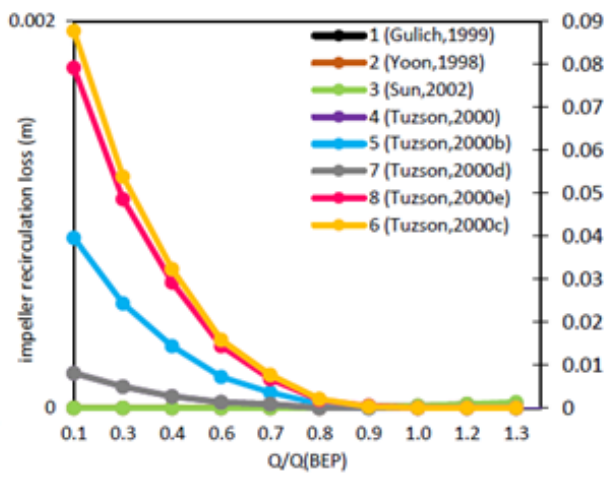

(f)

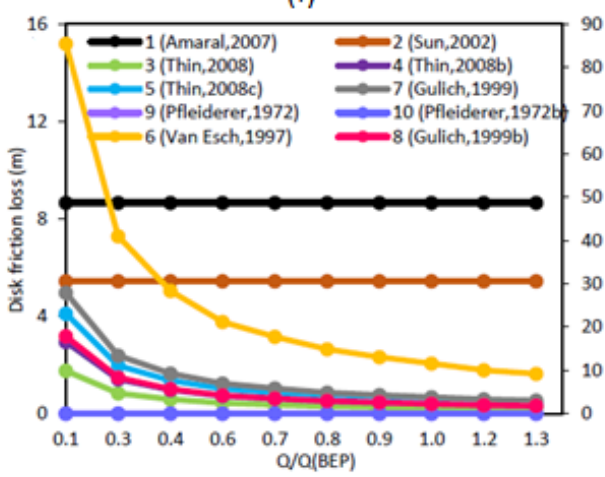

Figure 2. Formulations used for: (a) net theoretical head, (b) impeller friction loss (ninth and tenth formulations on the right), (c) impeller shock loss, (d) impeller recirculation loss (sixth formulation on the right), (e) diffuser loss, and (f) disk friction loss (sixth and eighth formulations on the right), for $720 \mathrm{cP}$ and $3500 \mathrm{rpm}$.

difference among them is the shock factor used in the formulations. The fifth to seventh formulations in Table 3 extracted from Bing et al. (2012) presented a similar behavior. To adjust the coefficients of shock losses, a logarithmic regression technique was used (not shown). By comparing the present results with previous studies, the curves showed relatively similar behavior, except for the larger loss values due to high fluid viscosity. The high fluid viscosity propitiates more uniform fluid velocities at the impeller inlet, avoiding abrupt changes in flow direction and reducing impeller shock losses.
For the impeller recirculation loss (Fig. 2d), it is noted that second, third, fourth, fifth, and seventh formulations in Table 4 exhibit very similar curves. All the formulations for the recirculation losses resulted in curves that decay with flow rates at flow rates smaller than the BEP one, and are insignificant at flow rates larger than the BEP one. The sixth formulation in Table 4 resulted in a larger recirculation loss. The difference between the formulations is the value of the correction factor, which was adjusted using a logarithmic regression (not shown). The recirculation losses were relatively similar to the ones found in previous studies for less viscous fluids. 
(a)

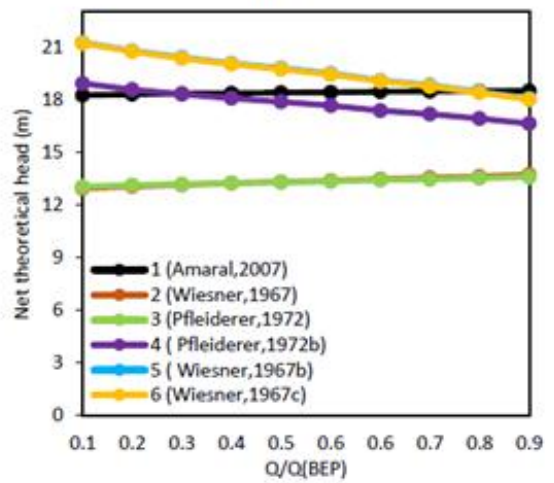

(c)

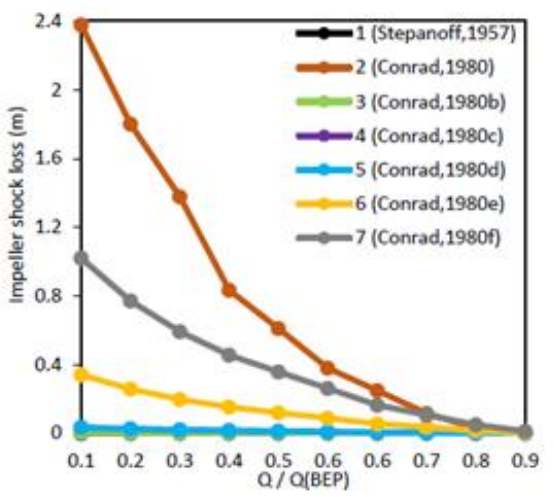

(e)

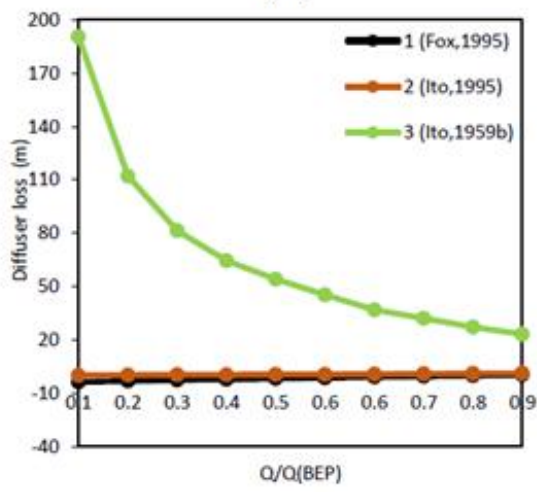

(b)

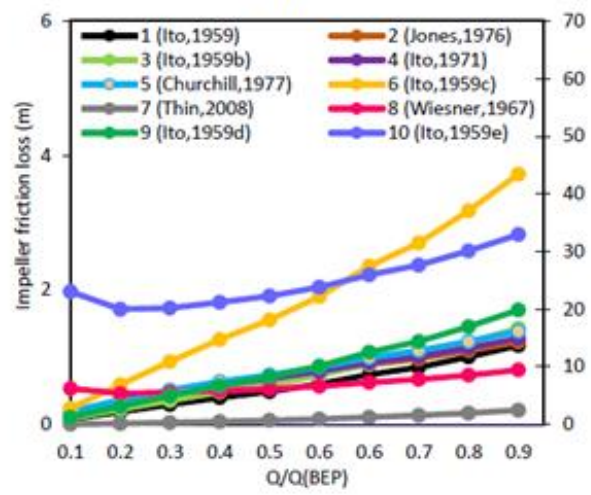

(d)

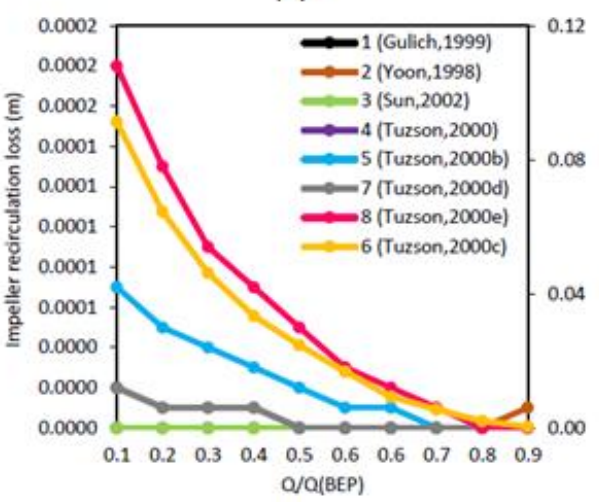

(f)

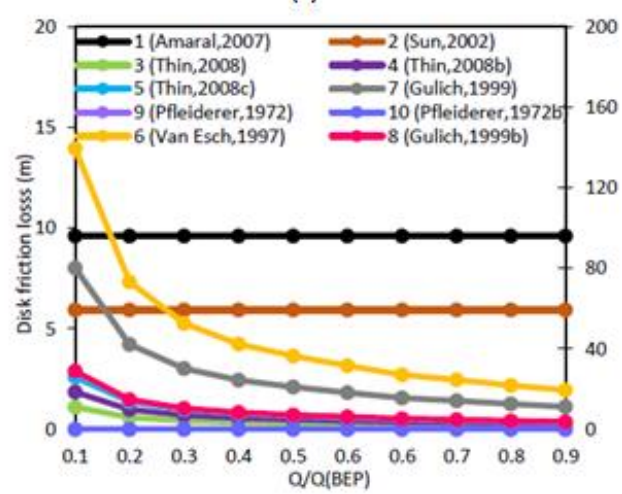

Figure 3. Formulations used for: (a) net theoretical head, (b) impeller friction loss (ninth and tenth formulations on the right), (c) impeller shock loss, (d) impeller recirculation loss (sixth formulation on the right), (e) diffuser loss, and (f) disk friction loss (sixth and eighth formulations on the right), for $1020 \mathrm{cP}$ and $3500 \mathrm{rpm}$.

By analyzing the diffuser friction losses (Fig. 2e), it was verified for the first formulation in Table 5 (Amaral, 2007), highly positive values at higher flow rates, and negative values at lower flow rates. For higher flow rates, the diffuser acts as a power dissipater. The second formulation in Table 5 resulted in a decrease of this loss with flow rate, presenting a similar behavior to the impeller friction loss. The third formulation in Table 5 (Ito, 1959) resulted in a larger loss, and in an approximately parabolic profile for this loss. The third formulation resulted in a greater loss $1 \approx$ $200 \%$ ) for the ones found by previous studies for less viscous fluids. This shows a strong impact of high fluid viscosity on diffuser friction losses.

For the disk friction losses (Fig. 2f), first and second formulations in Table 6 (Amaral, 2007) resulted in constant losses. The difference between these two formulations comes from the empirical kinematic factor used. Stepanoff (1957) described the behavior that propitiate losses in the remaining formulations in Table 6. According to this author, the disk friction losses decay with the increase of the impeller power, raising the temperature of the fluid contained in the interstices between the 


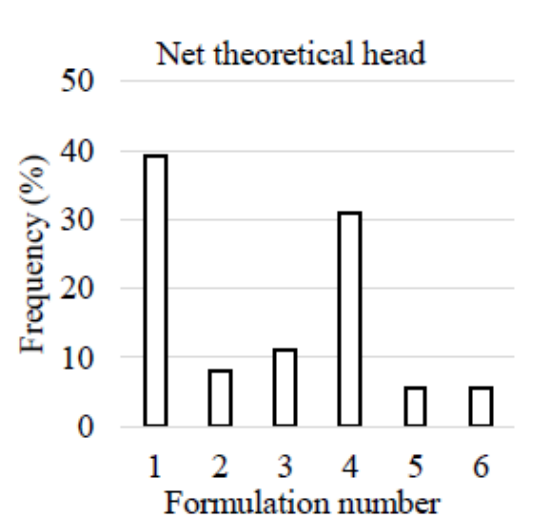

Impeller recirculation loss

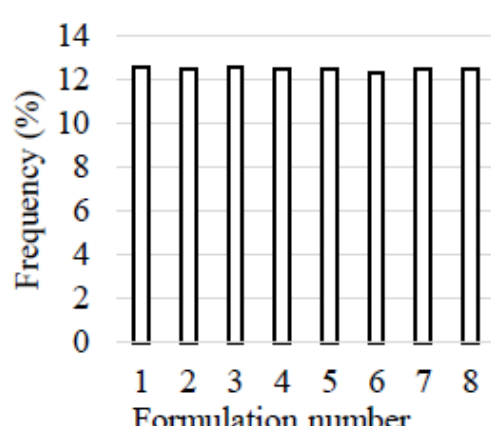

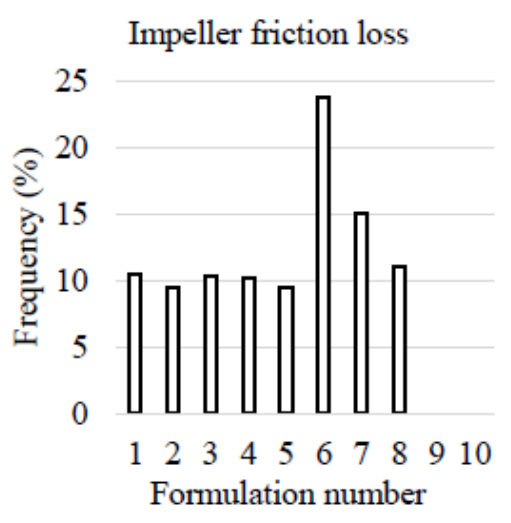

Diffuser loss

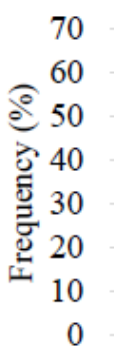

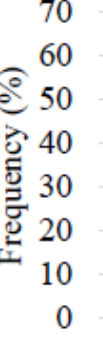

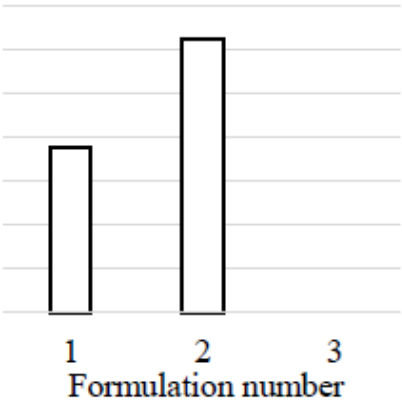

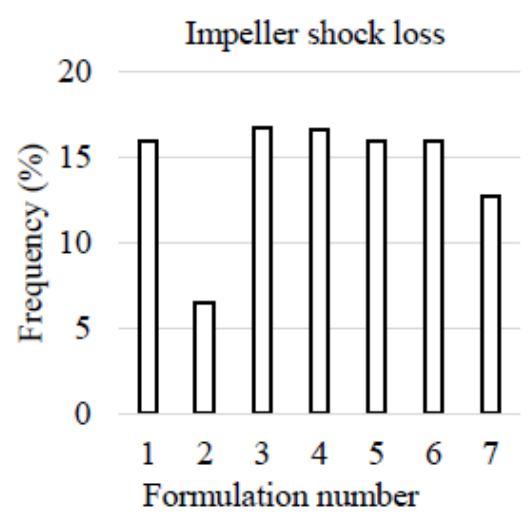

Disk friction loss

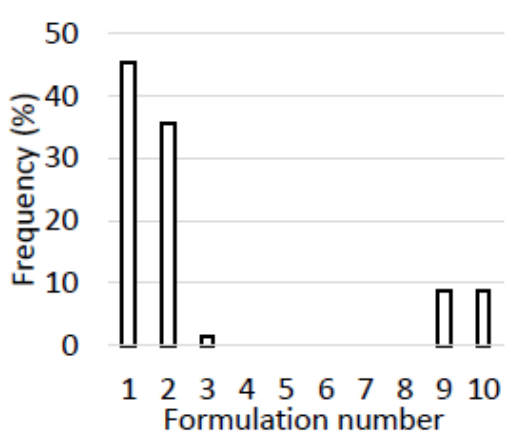

Figure 4. Frequency distributions of formulations used for net theoretical head, impeller friction loss, impeller shock loss, impeller recirculation loss, diffuser loss, and disk friction loss, for 720 cP and 3500 rpm.

impeller and the carcass of the pump. Third to fifth formulations in Table 6 (Thin et al., 2008) provided larger losses, so that their maximum values differed only concerning the value of the coefficient of disk friction. The coefficient of disk friction was adjusted using a logarithmic regression (not shown). The sixth and eighth formulations in Table 6 resulted in very different curves concerning the previous studies for less viscous fluids. Both formulations exhibited much larger losses than the ones used by the above mentioned author.

By analyzing net theoretical head and pressure losses of the flow in a pump stage for Case 2 (Fig. $3)$, one can note relatively similar results to the ones for Case 1, except for the smaller range of flow rates and the different magnitudes of the net theoretical head and the losses. Yet, the BEP flow rate corresponding to Case 2 was extrapolated by Amaral (2007). Another important feature is the first formulation for the impeller shock loss (Amaral, 2007), which was insignificant for Case 2 (in opposition to the previous cases, the coefficient of the impeller shock loss was assumed null).

\subsection{Analysis of pressure losses}

This section presents the analyses of four cases discussed in the sequence.

\subsubsection{Case $1(\mu=720 \mathrm{cP}$ and $\mathbf{N}=3500$ rpm)}

The largest and the smallest RMSE values among the 100800 actual pump heads estimated by the theoretical model relative to the experimental head were around $96.65 \mathrm{~m}$ (or $867 \%$ ) and $0.22 \mathrm{~m}$ (or 2.8\%), respectively. This range of RMSE shows that the combination of formulations provides accurate results and discrepancies, being the last ones considerably larger than the ones found in previous studies for less viscous fluids.

The 1008 most accurate combinations of formulations ( $1 \%$ of the total number) and their frequency distributions for each term of the head equation were estimated by the theoretical model fixing a RMSE smaller than $0.91 \mathrm{~m}$. Figure 4 shows the frequency distributions of formulations for each term of the head equation. First and fourth 
Table 7. List of the most accurate combinations of formulations for $720 \mathrm{cP}$ and $3500 \mathrm{rpm}$.

\begin{tabular}{lccccccccc}
\hline Combination of formulations & \multicolumn{2}{l}{$\mathrm{H}_{\text {theoretical }} \mathrm{h}_{\text {friction }}$} & $\mathrm{h}_{\text {shock }} \mathrm{h}_{\text {recirculation }}$ & $\mathrm{h}_{\text {diffuser }}$ & $\mathrm{h}_{\text {disk }}$ & RMSE (m) & RMSE (\%) \\
\hline 1 (with adjusted coefficients) & 1 & 8 & 3 & 1 & 1 & 1 & 0.228 & 2.80 \\
1 (without adjusted coefficients) & 1 & 1 & 3 & 1 & 1 & 1 & 0.322 & 3.58 \\
\hline
\end{tabular}

formulations for the net theoretical head in Table 1 , with decaying heads with flow rate, are the most frequent $(70 \%$ of the total number). By comparing these distributions with the ones from previous studies for less viscous fluids, the formulations that do not consider pre-rotation of the flow were less frequent. For the impeller friction losses, similar frequencies are observed from the first to the fifth and eighth formulations in Table 2, indicating that the values of these losses may represent, more realistically, the head in a pump stage. One can also observe that the sixth formulation is the most frequent $(24 \%)$ one. However, the formulations that presented the largest impeller friction losses (ninth and tenth formulations in Table 2) were less frequent $(0 \%)$. The use of correction factors that consider rectangular, curved, and rotating channel represented best the impeller friction loss.

For the impeller shock losses, similar frequencies are observed between the first, third, fourth, fifth, sixth, and seventh formulations in Table 3 (Fig. 4). However, the second formulation in Table 3 is less present (6\%). This formulation resulted in smaller shock coefficients, indicating it is not satisfactory for computing impeller shock losses due to the value of the empirical coefficient used by Thin et al. (2008). For the impeller recirculation losses, similar frequency distributions are observed, so that all of them use a recirculation factor depending on pump geometry and fluid viscosity. As a result, the formulations for the recirculation losses seem unconsolidated in this first analysis. For the diffuser friction losses, a considerably larger frequency of the second formulation is observed (60\%), followed by the first formulation (38\%). Although both frequencies are significant, the two formulations were very different. The second formulation had very small losses in the diffuser, while the first one provided pressure gains in the diffuser at lower flow rates. This result was relatively similar to the ones obtained by previous studies for less viscous fluids. For the disk friction losses, the first formulation is dominant (45\%), followed by the second formulation (35\%). This distribution reveals that an approximately constant disk friction loss reproduces the pump head more accurately. This was also observed in previous studies for less viscous fluids (except for a larger frequency of the second formulation).

The selection of the most accurate combinations of formulations for the pump head made by the theoretical model is presented in Table 7. For this selection, a RMSE value smaller than $0.22 \mathrm{~m}$ was fixed. The RMSE has similar values for the most accurate combinations $(0.228 \mathrm{~m}$, or $2.8 \%)$ so that all of them simulated the pump head with good accuracy. So, all the selected combinations satisfy the API RP 11S2 (1997), which consider a maximum error of $5 \%$. The combination selected without the adjustment of the coefficients of shock, recirculation, and disk friction losses also showed good accuracy $(0.322 \mathrm{~m}$, or $3.58 \%)$, satisfying API RP 11 S2 (1997). One can observe a consistency between the most accurate combinations and the most frequent formulations (Fig. 4), except for formulation of impeller friction and diffuser friction losses.

Figure 5 shows the effect of pressure losses on the pump head for the most accurate combination of formulations selected previously. The variation of fluid viscosity affects significantly the performance of the pump, as observed by Dunaiski (2015). Impeller friction and shock losses were of little importance, barely changing the pump's curve. Crossing curves are due to the pressure gain at the diffuser inlet, as also found in previous studies (Amaral, 2007; Dunaiski, 2015; Sirino, 2013). However, there are no pump curves in the literature showing this behavior. The pressure gain in the diffuser is not larger than the pressure losses caused by viscous forces acting on the flow, especially for the highly viscous flow studied in this work. 


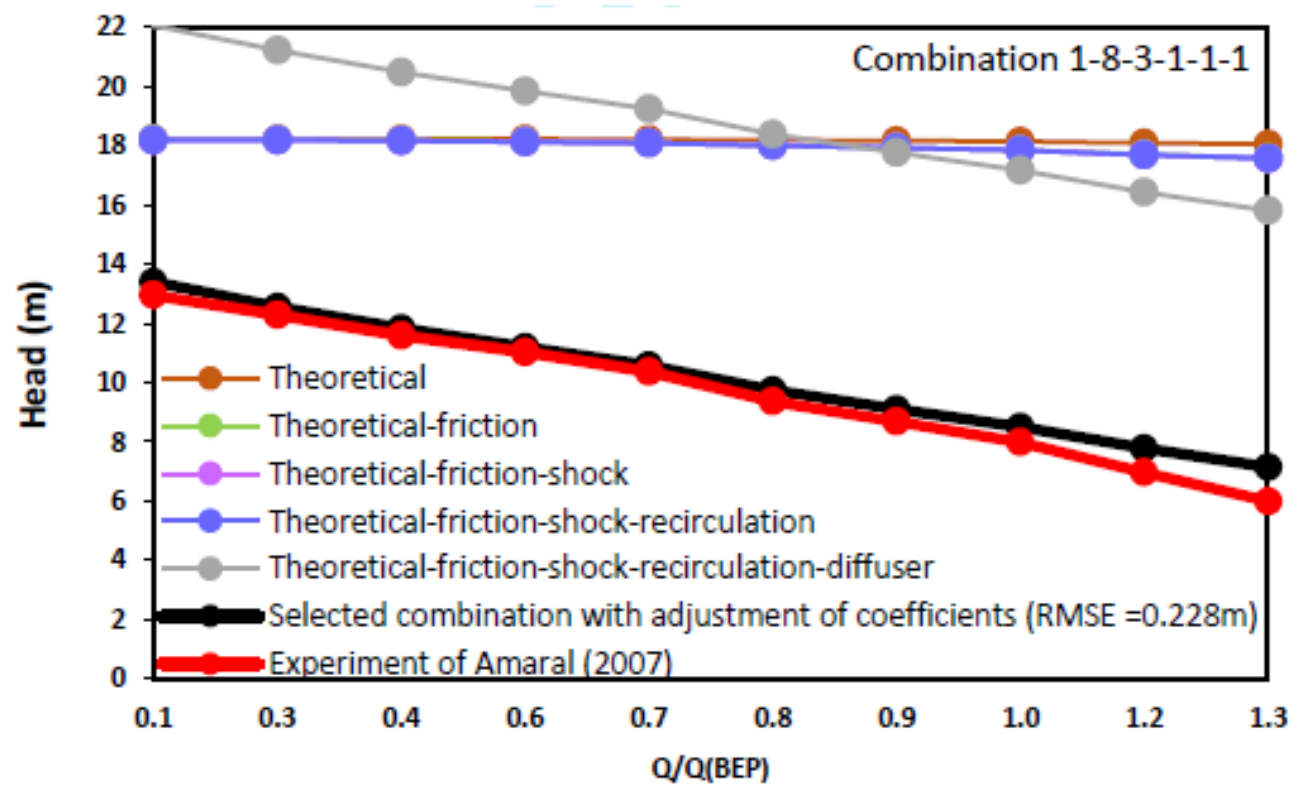

Figure 5. Effect of the pressure losses on the pump head for the most accurate combination selected by the theoretical model using adjusted coefficients for $720 \mathrm{cP}$ and $3500 \mathrm{rpm}$.

To obtain the combination of formulations that satisfies Case 1, the physical aspect of the flow on the pump stage was considered. Hence, the most precise formulations selected did not satisfy physically the flow within a centrifugal pump stage. As a result, it is proposed the use of Vieira et al.'s (2015) combination (proposed for $270 \mathrm{cp}$ and 3500 rpm) to attend the physical characteristics of the highly viscous flow. This resulted in a RMSE around $0.028 \mathrm{~m}(3.05 \%)$, and it is composed by the following formulations:

- (1) $H_{\text {theoretical }}$ : The net theoretical head of Amaral (2007), which considers pre-rotation of the flow at impeller inlet and corrects the velocity and angle of the flow at impeller outlet by a kinematic factor obtained by experimental adjustments;

- (6) $h_{\text {friction: }}$ The impeller friction loss of Sun and Prado (2002), with a specific equation for mixed flow pump and corrected friction factor for the rectangular, curved, and rotating channel;

- (3) $h_{\text {shock: }}$ The impeller shock loss of Bing et al. (2012);

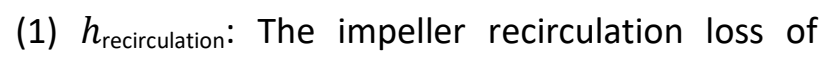
Amaral (2007), with a null value (first formulation);

(2) $h_{\text {diffuser: }}$ The diffuser friction loss of Sun et al. (2001) and Sun and Prado (2002, 2003), with friction factor containing two corrections, and;
(2) $h_{\text {disk: }}$ The disk friction loss of Sun and Prado (2002) and Amaral (2007).

\subsubsection{Case $2(\mu=1020 \mathrm{cP}$ and $\mathrm{N}=3500$ rpm)}

The largest and the smallest RMSE values among the 100800 actual pump heads estimated by the theoretical model were about $70 \mathrm{~m}(750 \%)$ and $0.7 \mathrm{~m}$ (or $0.33 \%$ ), respectively. The most accurate 1008 combinations of formulations (1\% of the total) and the frequency distributions of formulations for each term of the head equation were estimated by fixing a RMSE value smaller than $0.73 \mathrm{~m}$.

Figure 6 shows the frequency distributions of formulations for each term of the head equation. It is noted that the fourth formulation for the net theoretical head in Table 1 was the most frequent $(30 \%)$, followed by the first $(23 \%)$ and third $(17 \%)$ formulations. For the impeller friction losses (Table 2 ), the sixth formulation was the most frequent (40\%). On the other hand, the formulations that presented the largest impeller friction losses (ninth and tenth) were less frequent (0\%). As in Case 1 , there are well-distributed frequencies between the formulations for the impeller shock (Table 3 ) and recirculation losses (Table 4 ) in Case 2, except by the seventh formulation for the shock loss, which is much less frequent (10\%). For the diffuser friction losses (Table 5), a considerably larger frequency of 

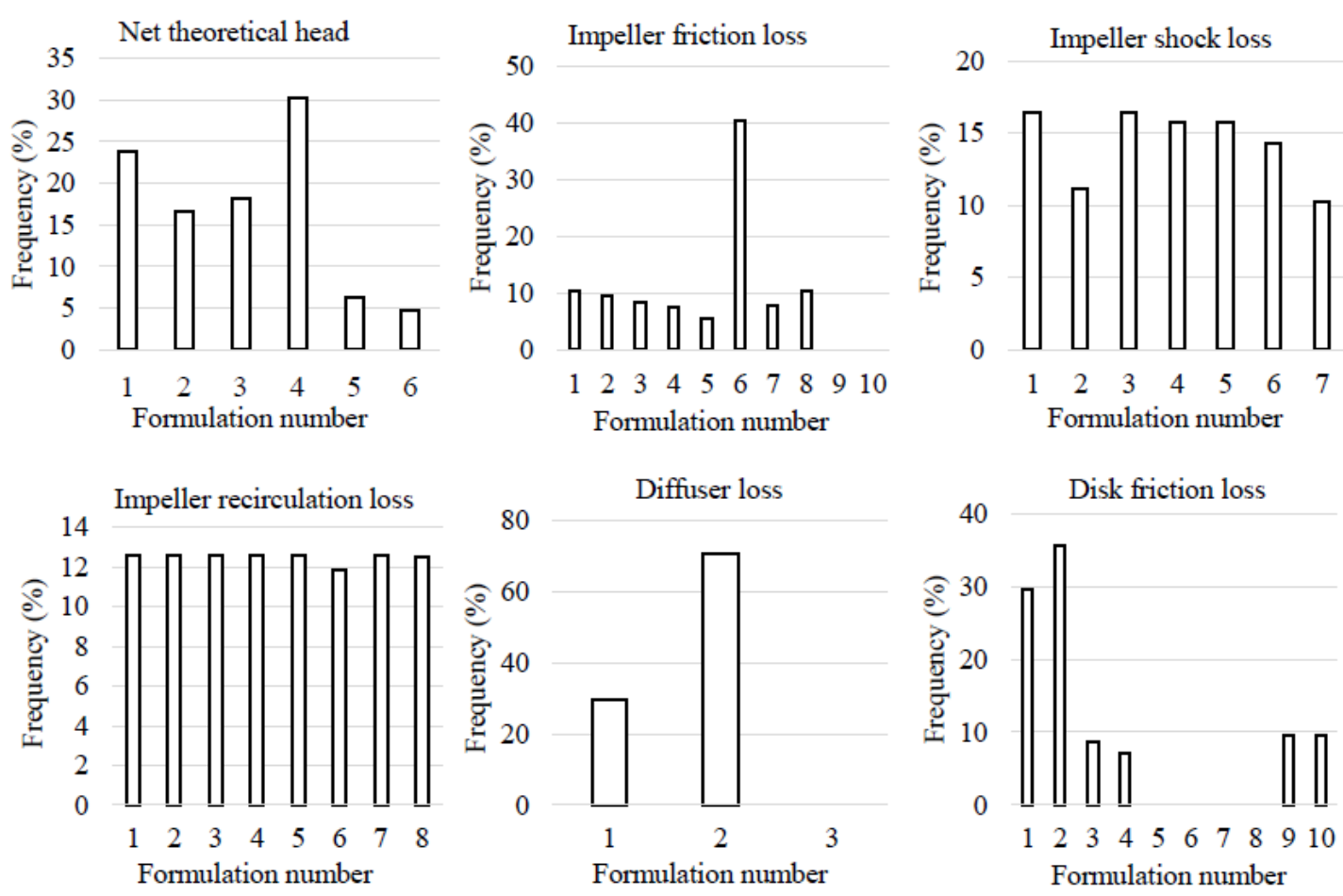

Figure 6. Frequency distributions of formulations used for net theoretical head, impeller friction loss, impeller shock loss, impeller recirculation loss, diffuser loss, and disk friction loss, for $1020 \mathrm{cP}$ and $3500 \mathrm{rpm}$.

the second formulation (71\%) is noted, followed by the first formulation (29\%). For the disk friction losses (Table 6), the second formulation was more frequent $(36 \%)$, followed by the first formulation (29\%).

The selection of the most accurate combinations for the pump head made by the theoretical model is shown in Table 8. In this case, a RMSE value smaller than $0.062 \mathrm{~m}$ was fixed. The RMSE was small for all combinations $(0.063 \mathrm{~m}$, or $0.59 \%)$ so that the formulations with adjusted empirical coefficients simulated the pump head more accurately. Both combinations satisfied API RP 11S2 (1997). The most accurate combination is also consistent with the most frequent formulations (Fig. 4), being composed by the following formulations:

- (4) $H_{\text {theoretical: }}$ The net theoretical head of Wiesner
(1967), which does not consider the pre-rotation of the flow at impeller inlet and corrects the velocity and angle of the flow at impeller outlet by a kinematic factor obtained from experimental adjustments (fourth formulation);

- (4) $h_{\text {friction: }}$ The impeller friction loss of Ito (1959), with a specific equation for mixed flow pump, and a correction factor for the curved channel;

- (6) $h_{\text {shock }}$ : The impeller shock loss of Conrad et al. (1980);

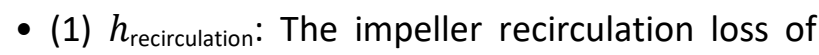
Amaral (2007), with null value;

- (2) $h_{\text {diffuser }}$ : The diffuser friction loss of Sun et al. (2001) and Sun and Prado (2002, 2003), with friction factor containing two corrections, and;

- (2) $h_{\text {disk }}$ : The disk friction loss of Amaral (2007).

Table 8. List of the most accurate combinations of formulations for $1020 \mathrm{cP}$ and $3500 \mathrm{rpm}$.

\begin{tabular}{lccccccccc}
\hline Combination of formulations & \multicolumn{2}{c}{$\mathrm{H}_{\text {theoretical }} \mathrm{h}_{\text {friction }} \mathrm{h}_{\text {shock }} \mathrm{h}_{\text {recirculation }} \mathrm{h}_{\text {diffuser }} \mathrm{h}_{\text {disk }}$} & $\mathrm{RMSE}(\mathrm{m})$ & \multicolumn{2}{c}{$\mathrm{RMSE}(\%)$} \\
\hline 1 (with adjusted coefficients) & 4 & 4 & 6 & 1 & 2 & 2 & 0.062 & 0.59 \\
1 (without adjusted coefficients) & 4 & 4 & 3 & 2 & 2 & 2 & 0.126 & 1.08 \\
\hline
\end{tabular}




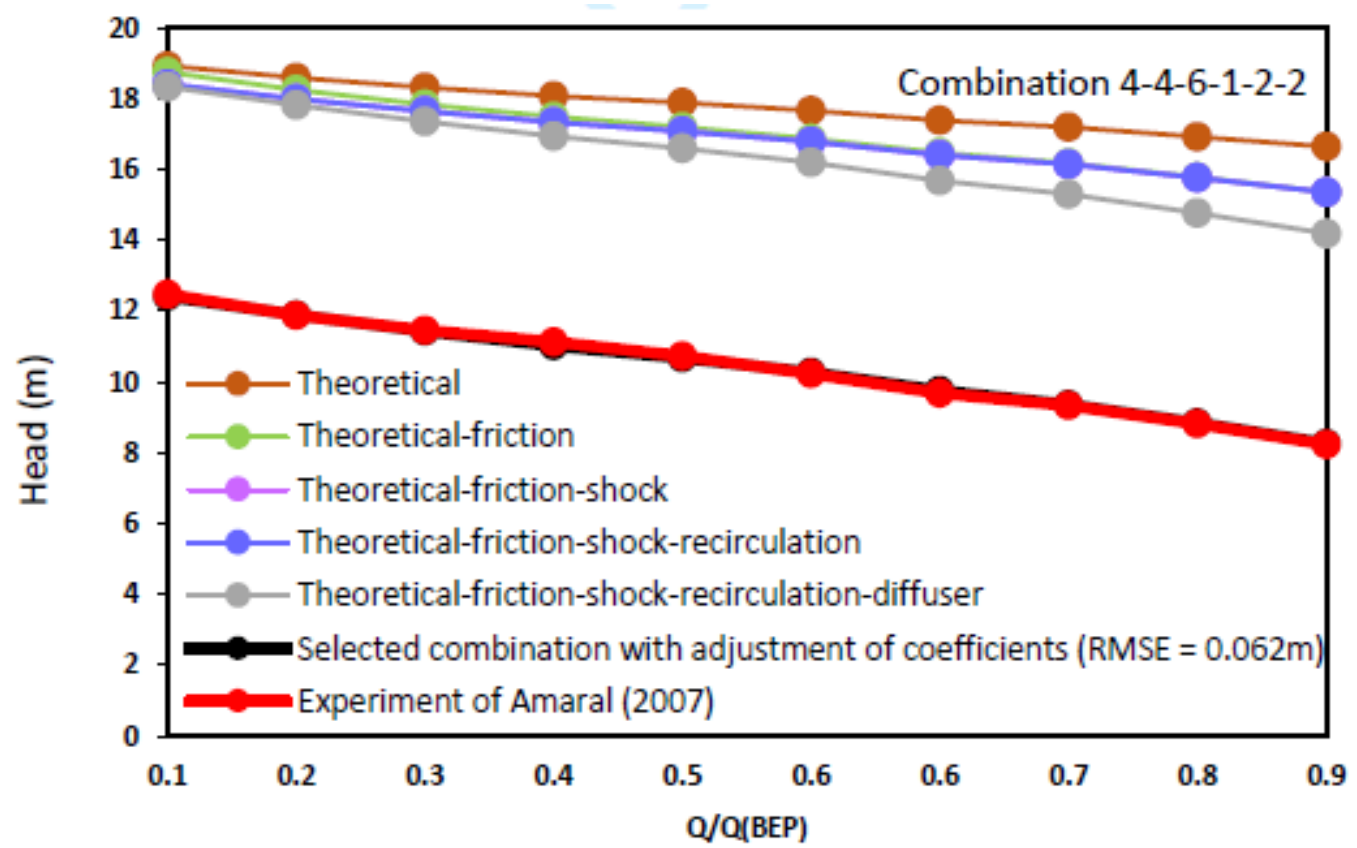

Figure 7. Effect of the pressure losses on the pump head for the most accurate combination selected by the theoretical model using adjusted coefficients for $1020 \mathrm{cP}$ and $3500 \mathrm{rpm}$.

Figure 7 shows the effect of pressure losses on the pump's head for the most accurate combination estimated by the theoretical model with adjusted coefficients. The simulated pump head is also compared with the experimental head of Amaral (2007). Pump curves are consistent with values found in the literature (no crossing curves), validating the combination of formulations selected.

\subsubsection{Case $3(\mu=720 \mathrm{cP}$ and $\mathrm{N}=1800$ rpm) and Case 4 ( $\mu=1020 \mathrm{cP}$ and $N$ $=1800 \mathrm{rpm}$ )}

Cases 3 and 4 refer to fluids containing high viscosity and very high viscosity, respectively, at smaller flow rates. Both cases are useful to analyze the variability of pump head and pressure losses with pump rotation. Since the 1800 -rpm rotation is less used in the industry, only a summary of the results is presented for both cases.

The selection of the most accurate combinations for the pump head made by the theoretical model for Cases 3 and 4 are presented in Tables 9 and 10, respectively. According to the literature, a slower pump rotational velocity implies a stronger degradation of the pump, which is related directly to the smaller energy provided by the pump to the flow. For this reason, the flow has a smaller capacity to acquire the same head provided by a larger pump rotation, reducing the head in the pump stage and, consequently, generating larger discrepancies. For Case 3, the fifth formulation was selected for the net theoretical head (Table 1); the third and first formulations were selected for the impeller friction loss (Table 2); the seventh and fourth formulations were selected for the impeller shock loss (Table 3); the second formulation was selected for the diffuser friction loss (Table 5); and the first

Table 9. List of the most accurate combinations of formulations for $720 \mathrm{cP}$ and $1800 \mathrm{rpm}$.

\begin{tabular}{lccccccccc}
\hline Combination of formulations & $\mathrm{H}_{\text {theoretical }}$ & $\mathrm{h}_{\text {friction }}$ & $\mathrm{h}_{\text {shock }}$ & $\mathrm{h}_{\text {recirculation }}$ & $\mathrm{h}_{\text {diffuser }} \mathrm{h}_{\text {disk }}$ & RMSE $(\mathrm{m})$ & RMSE $(\%)$ \\
\hline 1 (with adjusted coefficients) & 5 & 3 & 7 & 1 & 2 & 1 & 0.022 & 1.18 \\
1 (without adjusted coefficients) & 5 & 1 & 4 & 1 & 2 & 1 & 0.028 & 1.65 \\
\hline
\end{tabular}


Table 10. List of the most accurate combinations of formulations for $1020 \mathrm{cP}$ and $1800 \mathrm{rpm}$.

\begin{tabular}{lccccccccc}
\hline Combination of formulations & $H_{\text {theoretical }}$ & $h_{\text {friction }}$ & $h_{\text {shock }}$ & $h_{\text {recirculation }}$ & $h_{\text {diffuser }}$ & $h_{\text {disk }}$ & RMSE $(m)$ & RMSE (\%) \\
\hline 1 (with adjusted coefficients) & 1 & 3 & 7 & 1 & 1 & 1 & 0.073 & 2.58 \\
1 (without adjusted coefficients) & 1 & 2 & 1 & 1 & 1 & 1 & 0.092 & 11.83 \\
\hline
\end{tabular}

formulation was selected for the disk friction loss (Table 6). For the impeller recirculation loss (Table 4), several formulations could be selected due to very small associated errors. Another point is that the curve of the pump's head, generated by both combinations, showed consistency with respect to the literature (not shown), resulting in a RMSE around 1.18\%, and satisfying API RP 11 S2 (1997). This combination is composed by the following formulations:

- (5) $H_{\text {theoretical: }}$ The net theoretical head of Wiesner (1967);

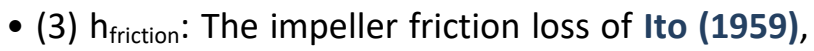
containing a specific equation for mixed flow pump and the correction factor for the curved channel;

- (7) $h_{\text {shock: }}$ : The impeller shock loss of Conrad et al. (1980);

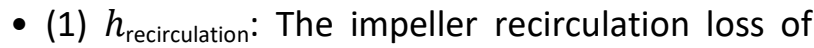
Amaral (2007), with null value;

- (2) $h_{\text {diffuser: }}$ The diffuser friction loss of Sun and Prado (2002 and 2003), with friction factor containing two corrections, and;

- (1) $h_{\text {disk }}:$ The disk friction loss of Amaral (2007).

For Case 4 (Table 10), the first formulation for the net theoretical head (Table 1), the third formulation for the impeller friction loss (Table 2), the seventh formulation for the impeller shock loss (Table 3), the first formulation for the diffuser friction loss (Table 5), and the first formulation for the disk friction loss (Table 6) were selected primarily due to their best accuracy. However, pump curves generated by both combinations exhibited crossing curves, being inconsistent with the results available in the literature (not shown). For this reason, we selected a different combination that was both accurate and physically consistent. The combination found resulted in a RMSE around $0.15 \mathrm{~m}$ (or $8 \%$ ), not satisfying the API RP $11 S 2$ (1997). This combination is composed by the following formulations:
- (5) $h_{\text {theoretical: }}$ The net theoretical head of Wiesner (1967), which considers the pre-rotation of the flow at impeller inlet and corrects the velocity and angle of the flow at impeller outlet by a kinematic factor obtained from experimental adjustments;

- (1) $h_{\text {friction: }}$ The impeller friction loss of Ito (1959), containing a specific equation for mixed flow pump and the correction factor for the curved channel;

- (1) $h_{\text {shock: }}$ The impeller shock loss of Stepanoff (1957);

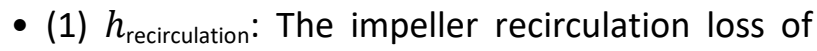
Amaral (2007), with null value;

- (2) $h_{\text {diffuser: }}$ The impeller friction loss of Sun and Prado $(2002,2003)$, with friction factor containing two corrections, and;

- (1) $h_{\text {disk: }}$ :The disk friction loss of Amaral (2007).

\subsection{Comparison with previous studies}

Table 11 shows the main results obtained in this study and previous studies for less viscous fluids. It is noted that the accuracies estimated in this study were usually larger than the ones from Vieira et al. (2015). This shows the difficulty of the theoretical modeling to simulate the pump's head more accurately for a highly viscous fluid. Besides, the adjustment of coefficients for impeller shock losses, impeller recirculation losses, and disk friction losses for highly viscous fluids contributed significantly to decrease the discrepancies found initially in this study. Consequently, only one studied flow case (Case 4) did not satisfy API RP 11S2 (1997).

By analyzing the formulations proposed in this study and by Vieira et al. (2015) (Table 11), the first formulation for the impeller recirculation loss (Table 4) and the second formulation for the diffuser friction loss (Table 5) were present in all the flow cases studied. The remaining formulations were very different one another, which shows a larger variability of formulations with fluid viscosity 
Table 11. Summary of the results obtained in the present work and in previous studies.

\begin{tabular}{|c|c|c|c|c|c|c|c|c|}
\hline & \multirow[t]{2}{*}{ Operational case } & \multicolumn{5}{|c|}{ Proposed combination } & \multicolumn{2}{|r|}{ RMSE (\%) } \\
\hline & & $\mathrm{H}_{\text {theoretical }}$ & $h_{\text {friction }}$ & $h_{\text {shock }}$ & $\mathrm{h}_{\text {recirculation }}$ & $h_{\text {diffuse }}$ & $\mathrm{h}_{\text {disk }}$ & \\
\hline \multirow{4}{*}{ Present work } & $720 \mathrm{cP}$ and $3500 \mathrm{rpm}$ & 1 & 6 & 3 & 1 & 2 & 2 & 3.05 \\
\hline & $1020 \mathrm{cP}$ and $3500 \mathrm{rpm}$ & 4 & 4 & 6 & 1 & 2 & 2 & 0.59 \\
\hline & $720 \mathrm{cP}$ and $1800 \mathrm{rpm}$ & 5 & 3 & 7 & 1 & 2 & 1 & 1.18 \\
\hline & $1020 \mathrm{cP}$ and $1800 \mathrm{rpm}$ & 5 & 1 & 1 & 1 & 2 & 1 & 8.00 \\
\hline \multirow{4}{*}{ Vieira et al. (2015) } & $1 \mathrm{cP}$ and $3500 \mathrm{rpm}$ & 5 & 4 & 6 & 1 & 2 & 2 & 3.10 \\
\hline & $270 \mathrm{cP}$ and $3500 \mathrm{rpm}$ & 1 & 6 & 3 & 1 & 2 & 2 & 3.20 \\
\hline & $1 \mathrm{cP}$ and $1800 \mathrm{rpm}$ & 6 & 7 & 6 & 1 & 2 & 2 & 7.20 \\
\hline & $270 \mathrm{cP}$ and $1800 \mathrm{rpm}$ & 1 & 6 & 3 & 1 & 2 & 2 & 2.40 \\
\hline
\end{tabular}

and pump rotation in this study. It is also important to discuss the invalidity of each selected combination of formulations found in this study concerning the four studied flow cases. In other words, no unique combination can simulate the pump head accurately for the four flow cases. This last result was confirmed by computing the RMSE values for the simulated head (corresponding to each selected combination of formulations) relative to the experimental head, for the four flow cases studied.

\section{CONCLUSIONS}

The effects of high fluid viscosity on pressure losses of the flow in an ESP stage were studied in the present work. The pump was a GN7000 model working in two rotations ( $3500 \mathrm{rpm}$ and $1800 \mathrm{rpm}$ ), and the study was performed for two high fluid viscosities (720 cp and $1020 \mathrm{cP}$ ), in four flow cases. The flow cases were based on the experimental study of Amaral (2007). The pressure losses in a pump stage were estimated using the theoretical model developed by Vieira et al. (2015). Also, the empirical coefficients present in the theoretical model had to be adjusted due to the large fluid viscosity. The pressure losses were validated using experimental heads for a pump stage and statistical analyses, and the study assumed single-phase, Newtonian, incompressible, and isothermal flow. The main conclusions about this study are presented below.

1. For high fluid viscosities, the shock and recirculation losses of the impeller do not impact significantly the pump's head, in opposition to the friction losses of the impeller, diffuser, and disk. This is favored by more intense viscous forces existent in the flow;

2. The theoretical modeling of the highly viscous flow using original empirical coefficients (not adjusted) for the pressure losses shows large inaccuracies for the pump head, not satisfying the criterion established by API RP 11 S2 (1997). The adjustments of these coefficients using logarithmic regression produced more accurate results and satisfied the criterion used in mostly studied flow cases;

3. The effect of the high fluid viscosity on the pump's head resulted in $50 \%$ of the studied flow cases in which statistical analysis was sufficient to select the most accurate combinations (Cases 2 and 3 ). However, there were $50 \%$ of the flow cases in which was also necessary to consider the physical behavior of the flow (Cases 1 and 4). This is due to an inconsistency found between the pump curves simulated by the theoretical model and the pump curves presented in the literature;

4. The combinations of formulations proposed for each studied flow case presented the smallest errors in their respective cases. However, by applying a combination that was selected for one case in another one, considerable discrepancies were observed due to the large variability of formulations found for each flow case. Thus, a unique combination of formulations was unable to reproduce accurately all pump head variations with pump rotation and especially with high fluid viscosity; 
5. The inaccuracies and variability of formulations for the highly viscous fluids studied in this work were considerably larger than the ones found in previous studies (for less viscous fluids), showing that the theoretical modeling of high viscous flow is a complex problem, and it needs more experimental datasets and additional studies to improve the predictability of the flow inside ESP systems.

\section{NOMENCLATURE}

$r$ or $R \quad$ radius $(\mathrm{m})$

$a \quad$ channel length $(\mathrm{m})$

$\alpha \quad$ absolute flow angle formed between the absolute velocity and its tangential component (rad)

$b \quad$ channel width $(\mathrm{m})$

b relative angle or blade angle formed between the blade and the tangent line (rad)

$C_{m} \quad$ disk friction coefficient

$C_{p} \quad$ diffuser loss coefficient

$\theta \quad$ radial component of the coordinate system

$\omega \quad$ shaft or impeller blades angular velocity rotating $\left(\mathrm{s}^{-1}\right)$

W

$N_{a}$

$D_{H}$

$r_{H}$

$S$

$k_{\text {shock }}$

$k_{\text {rec }}$

$D_{f}$

$D_{1 t}$

$g$

$p$

$\rho$

$f_{\text {disk }}$

$Q$

$k_{R R}$

$f_{\text {geo }}$

$f_{R S}$
$\mathrm{R}_{\mathrm{e}} \quad$ Reynolds number

$k_{D F} \quad$ friction factor corrected for thermal effects

$f_{\text {therm }}$ temperature factor for the disk friction

$K$ disc friction coefficient extracted from

Pfleiderer's abacus (Stepanoff, 1957)

\section{Subscripts}

1

2

2 dif or $2 d$

3dif or 3

$\mathrm{m}$

BEP

impeller inlet

impeller outlet

diffuser inlet

diffuser outlet

average of any parameter between the inlet and the outlet (of impeller or diffuser)

best efficient point (any parameter at maximum efficiency condition)

\section{ACKNOWLEDGMENTS}

The authors acknowledge Coordination for the Improvement of Higher Education Personnel (CAPES) and North Fluminense State University (UENF) for their financial and academic support, respectively.

\section{REFERENCES}

Amaral, G. D. L. Monophasic flow modeling of an ESP operating with viscous fluids. $260 f$. Dissertação de Mestrado. Programa de PósGraduação em Engenharia Mecânica, Universidade de Campinas, 2007. (in Portuguese)

API RP 11S2. Recommended Practice for Electric Submersible Pump Testing. Washington, DC: American Petroleum Institute, 1997.

Bing, H.; Tan, L.; Cao, S. Prediction method of impeller performance and analysis of loss mechanism for mixed-flow pump. Science China Technological Science, v.55, p.1988-1998, 2012. https://doi.org/10.1007/s11431-012-4867-9

Churchill, S. W. Friction-Factor equation spans all fluid -flow regimes. Chemical Engineering, v.7, p.91-92, 1977. 
Conrad, O.; Raif, K; Wessels, M. The calculation of performance maps for centrifugal compressors with vane-island diffusers. ASME 25th Annual International Gas Turbine Conference and 22nd Annual Fluids Engineering Conference on Performance Prediction of Centrifugal Pumps and Compressors, New Orleans, Louisiana, p.135-147, 1980.

Dunaiski, R. Simulação Numérica do Escoamento Monofásico em uma Bomba Centrífuga Radial. 101f. Dissertação de Mestrado. Universidade Tecnológica Federal do Paraná, Brazil. 2015. (in Portuguese)

Estevam, V. A. Mechanistic approach on gasliquid flow centrifugal pump performance prediction. 297f. Tese de Doutorado. Universidade de Campinas, 2002. (in Portuguese)

Fox, R. W.; McDonald, A. T. Introdução à Mecânica dos Fluidos, 5a Edição. Rio de Janeiro: Livros Técnicos e Científicos Editora, 506p, 2001. (in Portuguese).

Gülich, J. F. Pumping highly viscous fluids with centrifugal pump - Part 1. World Pumps, p.30-34, 1999. https://doi.org/10.1016/S0262-1762(00)87528-8

Gülich, J. F. Pumping highly viscous fluids with centrifugal pump - Part 2. World Pumps, p.39-42, 1999. https://doi.org/10.1016/S0262-1762(00)87492-1

Hein, F. J.; Parks, K. P.; Leckie, D.A.; Seibel, C. Foreword: Oil-sands and heavy-oil deposits: Local to global multidisciplinary collaboration. Bulletin of Canadian Petroleum Geology, v.64, p.99-105, 2017.

https://doi.org/10.2113/gscpgbull.64.2.99

Ito, H. Friction factors for turbulent flow in curved pipes. ASME, Journal of Basic Engineering, v.81, p.123-134, 1959.

https://doi.org/10.1115/1.4008390

Ito, H.; Nanbu, K. Flow in rotating straight pipes of circular cross section. ASME, Journal of Basic Engineering, v.93, p.383-394, 1971.

https://doi.org/10.1115/1.3425260

Jones, O. C. An improvement in the calculation of turbulent friction in rectangular ducts. Journal of Fluids Engineering, v.98, p.173-180, 1976.

https://doi.org/10.1115/1.3448250
Kruyt, N. P. Turbo Machines II - Lecture Notes. Department of Mechanical Engineering, University of Twente, Netherlands, p. 68, 2003.

Ladouani, A.; Nemdili, A. Influence of Reynolds number on net positive suction head of centrifugal pumps in relation to disc friction losses. Forschung Ingenieurwesen, v.73, p.173-182, 2009. https://doi.org/10.1007/s10010-009-0102-7

Paternost, G. M. Estudo experimental sobre bomba centrífuga operando com fluido viscoso e escoamento bifásico gás-líquido. 158p. Dissertação de Mestrado. Universidade Estadual de Campinas, 2013. (in Portuguese)

Pfleiderer, C.; Petermann, H. Máquinas de fluxo. Rio de Janeiro: Livros Técnicos e Científicos Editora, 454p, 1978. (in Portuguese)

Segala, W. Simulação Numérica Do Escoamento Monofásico no Primeiro Estágio de uma Bomba Centrífuga de Duplo Estágio. 150f. Dissertação de Mestrado. Universidade Tecnológica Federal do Paraná, 2010. (in Portuguese).

Shah, R. K. A Correlation for laminar hydrodynamics entry length solutions for circular and noncircular ducts. Journal of Fluids Engineering, v.100, p.177-179, 1978.

https://doi.org/10.1115/1.3448626

Sirino, T. Estudo Numérico da Influência da Viscosidade no Desempenho de uma Bomba Centrífuga Submersa. 114f. Dissertação de Mestrado. Programa de Pós-graduação em Engenharia Mecânica e de Materiais, Universidade Tecnológica Federal do Paraná, 2013. (in Portuguese)

Stepanoff, A. J. Centrifugal end Axial Flow Pups - Theory, Design and Application. Nova York: John Wiley \& Sons, 200p, 1957.

Sun, D.; Pessoa, R.; Prado, M. G. Single-phase model for radial ESP's performance. TUALP Annual Advisory Board Meeting, Houston/Texas, 2001.

Sun, D.; Prado, M. G. Single-phase model for ESP's performance. TUALP Annual Advisory Board Meeting, Tulsa/Oklahoma. 2002.

Sun, D.; Prado, M. G. Single-phase for ESP's head performance. SPE 80925-MS, SPE Production and Operations Symposium, Oklahoma. 2003. https://doi.org/10.2118/80925-MS 
Thin, K. C.; Khaing, M. M.; Aye, K. M. Design and Performance Analysis of Centrifugal Pump. World Academy of Science, Engineering and Technology, v.22, p.422-429, 2008.

Thomas, J. E.; Triggia, A.; Correia, C. A.; Filho, C. V.; Xavier, J. A. D.; Machado, J. C. V.; Filho, J. E. S.; Paula, J. L.; Rossi, N. C. M.; Pitombo, N. E. S., Gouveia, P. C. V. M., Carvalho, R. S.; Baragan, R. V. Fundamentos da Engenharia do Petróleo. Rio de Janeiro: Editora Interciência, 2001.

Tuzson, J. Centrifugal Pump Design. John Wiley and Sons Editora, USA, 2001.

Van Esch, B. P. M. Simulation of threedimensional unsteady flow in hydraulic pumps. Tese de Doutorado. University of Twente, 1997.

Vieira, T. S.; Siqueira, J. R.: Bueno, A. D.; Morales, E. M.; Estevam, V. Analytical study of pressure losses and fluid viscosity effects on pump performance during monophasic flow in ESP stage. Journal of Petroleum Science and Engineering, v.10, p.349-357, 2015. https://doi.org/10.1016/i.petrol.2015.01.014
Wiesner, F. J. A review of slip factors for centrifugal impellers. ASME, Journal of Engineering for Gas Turbines and Power, v.89, p.558-572, 1967. https://doi.org/10.1115/1.3616734

Yoon, E. S.; Oh, H. W.; Chung, M. K. Performance prediction of mixed-flow pumps. Journal of Power Energy, v.212, p.109-115, 1998. https://doi.org/10.1243/0957650981536637

Zhu, J.; Hattan, B.; Zenyan, X.; Hong-Quan, Z. CFD simulation and experimental study of oil viscosity effect on multi-stage electrical submersible pump (ESP) performance. Journal of Petroleum Science and Engineering, v.146, p.735745, 2016.

https://doi.org/10.1016/i.petrol.2016.07.033 